\title{
DETERMINATION OF PHENOLIC COMPOUNDS IN PRUNUS DOMESTICA LEAVES EXTRACT
}

\author{
Larysa Lenchyk
}

\author{
Department of Chemistry of Natural Compounds, \\ National University of Pharmacy, Kharkiv
}

\begin{abstract}
Qualitative composition and content of phenolic compounds in the dry extract obtained from plum leaves have been studied. Seven phenolic substances were found, including three hydroxycinnamic acids and four flavonoids. The dominant substances were chlorogenic acid $(2436.89 \mathrm{mg} / 100 \mathrm{~g})$ and rutin $(926.32 \mathrm{mg} / 100 \mathrm{~g})$. Free monosaccharides, such as glucose and rhamnose, were identified in the extract, and their amount was determined by HPLC. The obtained results showed the prospects of creating a new drug with antioxidant activity on the basis of the plum leaves dry extract.
\end{abstract}

Keywords: plum, leaves, extract, phenolic compounds

\section{INTRODUCTION}

Nowadays, one of the actual tasks of modern medicine is to expand the range of pharmaceuticals made from medicinal plants. Such pharmaceuticals have advantageous effectiveness, a wide range of therapeutic action, low toxicity and allergenicity. One of the ways to solve this task is the study and implementation of the plants used in ethnoscience into medical practice. One of such plants is plum Prunus domestica L., family Rosaceae. This fruit tree is widely cultivated in Ukraine, and approximately 4000 hectares are occupied by plum trees only in the Kharkiv, Poltava, Khmelnitskiy and Vinnitsa regions. Dried fruits are highly reputed in the ethnoscience medical practices for nutritive, laxative and digestive properties and are used for treatment of hypertension, diabetes, jaundice and fever. The recent studies showed

\footnotetext{
Address for correspondence:

Larysa Lenchyk

National University of Pharmacy,

53 Pushkinska Str.

61002 Kharkiv, Ukraine

e-mail: larysa.lenchyk@gmail.com
}

Received: August 11, 2015

Accepted: December 15, 2015 that fruits have antioxidant, anticancer, anti-hyperglycemic, anti-hyperlipidemic, antihypertensive, anti-osteoporosis, laxative and hepatoprotective activities (1-3). However, plum leaves are not widely used in medicine. According to the literature data, leaves contain polyphenols, vitamins, pectin and other biologically active compounds (3). Plant polyphenols are prospective for the study, since they have a wide range of pharmacological activity and play a leading role in regulation of oxidative balance in the human body (1).

At the department of Chemistry of Natural Compounds of National University of Pharmacy (NUPh) under supervision of professor V. S. Kyslychenko a dry extract from plum leaves was obtained by exhausting extraction of the plant raw material by $30 \%$ ethyl alcohol. At the department of Biological Chemistry of NUPh under the supervision of professor A. L. Zagayko it was proved that the extract had the antioxidant activity in concentration $1 \mathrm{mg} / \mathrm{g}$ and $2 \mathrm{mg} / \mathrm{g}$ in vitro. It was higher than $\alpha$-tocopherol. The research was carried out on the model of spontaneous lipid peroxydation in rat liver homogenate (1).

The study also revealed that the extract shows most powerful antioxidant effect in vivo at a dose of $25 \mathrm{mg} / \mathrm{kg}$ against acute tetrachloromethane induced hepatitis in rats, and exceeds the effect of the herbal 
drug Sylybor. The degree of antioxidant activity was evaluated by the level of TBA reactants in liver tissues (1).

The method of high performance liquid chromatography (HPLC) is widely used for the study of different groups of phenolic compounds extracted from plants. This method has a high sensitivity and accuracy. Therefore, the aim of our research was to investigate the phenolic constituents of the plum leaves dry extract by the HPLC method.

\section{MATERIALS AND METHODS}

The object of the study was the extract obtained by $30 \%$ ethyl alcohol from the Prunus domestica leaves collected in September 2014 after fruits harvesting in the Kharkiv region.

$0.5 \mathrm{~kg}$ of plum leaves, comminuted to size of $1-2$ $\mathrm{mm}$, was placed in the flask and $1.5 \mathrm{~L}$ of $30 \%$ ethyl alcohol was added. Extraction was carried out in water bath for two hours. The extraction was repeated three times with new portions of the extractant (1.0 L). The obtained extracts were combined, allow the solid material to settle for a day, filtered. The filtrate was evaporated to a dry extract using a rotary vacuum-evaporating device.

For preliminary identification of biologically active substances of the extract, such generally accepted research methods as qualitative reactions, paper chromatography (PC) and thin layer chromatography (TLC) were used.

Flavonoids were studied by TLC with valid samples of flavonoids in the solvent system glacial acetic acid - water - ethyl acetate (20:20:60). Obtained chromatograms were treated by solution of amino ethyl ester of diphenyl boric acid in methanol, and then by macrogol solution. After that, the plate was heated at a temperature of $100-105^{\circ} \mathrm{C}$ for $10 \mathrm{~min}$ and viewed in daylight $(4,9)$.

For identification of hydroxycinnamic acids, the method of two-dimensional PC was used in solvent systems: I-st direction - n-butanol - acetic acid water (4: 1: 2), and II-nd direction - 15\% acetic acid. Obtained chromatograms were treated by ammonia solution and azo coupling reagent $(4,9)$.

For hydrolysis, $300 \mu \mathrm{l}$ of $4 \%$ plum leaves extract alcohol solution was placed in a $2 \mathrm{ml}$ vial, and $300 \mu \mathrm{l}$ $6 \mathrm{~N}$ solution of hydrochloric acid in ethanol (1:1 by volume) was added. The hermetically sealed vial was heated in an oven at $100^{\circ} \mathrm{C}$ for 1 hour. After cooling, the content of the vial was centrifuged and transferred for analysis.

Qualitative composition and content of phenolic compounds in the plum leaves dry extract were studied by HPLC, with the Agilent Technologies chromatograph (model 1100) completed with continuous-flow vacuum degasifier G1379A, 4-channel pump of low pressure gradient G13111A, automatic injector G1313A, column oven G13116A, diode array detector G1316A (5-8).

The chromatographic column ZORBAX-SB C-18, $2.1 \times 150 \mathrm{~mm}$, filled with octadecyl silyl sorbent grained 3.5 microns was used for analysis.

Analysis was performed under the following conditions: temperature of the thermostat was 35 ${ }^{\circ} \mathrm{C}$; mobile phase flow rate $-0.25 \mathrm{ml} / \mathrm{min}$. Gradient regime of chromatography was used with a mobile phase solution $\mathrm{A}\left(0.1 \% \mathrm{H}_{3} \mathrm{PO}_{4}\right.$, in water) and solution $\mathrm{B}(\mathrm{MeOH})$ in a ratio of $90: 10$ (the first $8 \mathrm{~min}), 70: 30$ (8 to $25 \mathrm{~min}$ ), 20:80 (25 min). From 26 to $30 \mathrm{~min}$, only the solution B was used, and after again, solutions $A$ and $B$ in a ratio of 90:10 (30 to $35 \mathrm{~min}$ ) were used. The operating pressure of the eluent was 240 $300 \mathrm{kPa}$. These conditions refer to the known method and was performed with some modifications to the gradient (8).

Parameters of the analysis were the following: scale of measurement - 1.0; scan time - 0.5 seconds; options metering spectrum - each peak of 190-600 $\mathrm{nm}$. Identification of phenolic compounds was performed by the retention time of standards of hydroxycinnamic acids and flavonoids and their spectral characteristics (7-9). Each peak detected in the plum extract was identified by comparing retention time and UV spectra given by the diode array detector with the standards. Standards of flavonoids and hydroxycinnamic acids were dissolved in 50\% methanol to make a concentration of $0.0001-0.0006 \%$.The flavonoids, hydroxycinnamic acids were quantified by calibration with the standards.

Investigation of the monosaccharide content in the plum leaves dry extract before and after hydrolysis was carried out by HPLC with the chromatograph Agilent Technologies (model 1100) with refractometric detector. For this analysis, chromatograph- 
Larysa Lenchyk

ic column carbohydrate $7,8 \times 300 \mathrm{~mm}$ «Supelcogel$\mathrm{C} 610 \mathrm{H} »$ was used.

For the analysis, the following mode was set: mobile phase flow rate $0.5 \mathrm{ml} / \mathrm{min}$; eluting with $0.1 \%$ aqueous solution of $\mathrm{H}_{3} \mathrm{PO}_{4}$; operating pressure of the eluent - 33-36 kPa; column oven temperature $-30^{\circ} \mathrm{C}$; the sample volume was $5 \mu$ l. Identification of the sugars was carried out by the sugar standard samples retention time.

Sample of plum leaves was extracted in triplicate and analyzed by HPLC.

The statistical processing of results was carried out using the package Statistica 6.0. The error did not exceed $5 \%$.

\section{RESULTS}

After our preliminary study of biologically active substances in the plum leaves dry extract by TLC and PC with authentic samples, the presence of hydroxycinnamic acids and flavonoids, including chlorogenic acid and rutin, was established.

As a result of the study of the plum leaves extract by HPLC 7, the phenolic compounds were determined as derivatives of hydroxycinnamic acids and flavonoids. The amount of compounds was given per $100 \mathrm{~g}$ dry matter (Table 1). Graphical result of determination of phenolic compounds can be seen on Figure 1.

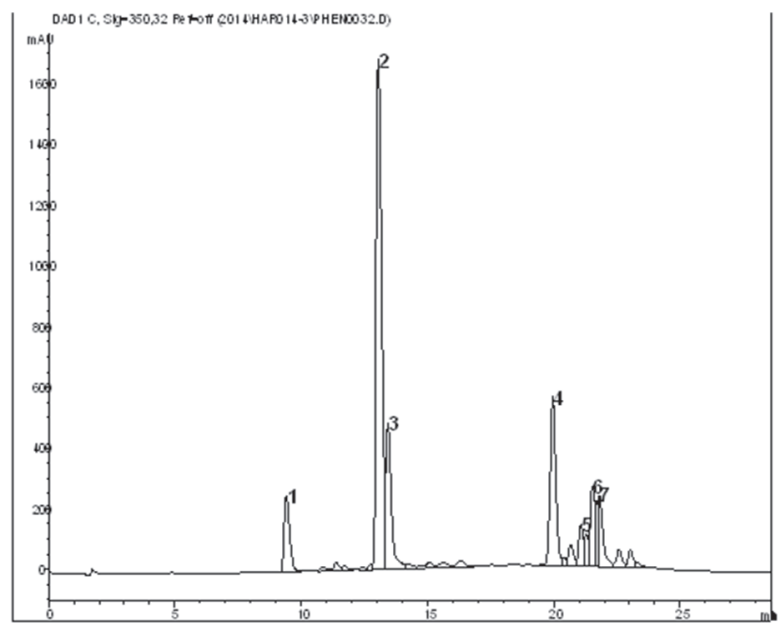

(A)
The predominant components were chlorogenic acid $2436.89 \pm 25.01 \mathrm{mg} / 100 \mathrm{~g}$ ) and rutin (926.32 $\pm 11.13 \mathrm{mg} / 100 \mathrm{~g})$.

The study of the monosaccharide composition of the plum leaves dry extract before and after hydrolysis revealed glucose and rhamnose before hydrolysis and three monosaccharides - glucose, galactose and rhamnose - after hydrolysis (Table 2).

Graphical result of determination of monosaccharides is shown on Figure 2.

After hydrolysis, free caffeic acid was found in the amount of $224.10 \pm 2.08 \mathrm{mg} / 100 \mathrm{~g}$ and aglycones quercetin, kaempferol, isoramnetin in the amount of $(\mathrm{mg} / 100 \mathrm{~g}) 311.13 \pm 3.14,115.54 \pm 2.28,119.44 \pm 2.30$, respectively. The amount of chlorogenic acid was $749.19 \pm 9.02 \mathrm{mg} / 100 \mathrm{~g}$; it was three times less than before hydrolysis.

The total amount of free sugar before hydrolysis in the extract was found as $4.10 \pm 0.08 \%$ and after hydrolysis it increased to $6.15 \pm 0.08 \%$. Free rhamnose was the most abundant substance in the extract.

\section{DISCUSSION}

The research established that the total amount of phenolic compounds, determined by HPLC, was $5.29 \pm 0.04 \%$; among them, the content of hydroxycinnamic acids was $-3.51 \pm 0.03 \%$ and flavonoids $1.78 \pm 0.02 \%$.

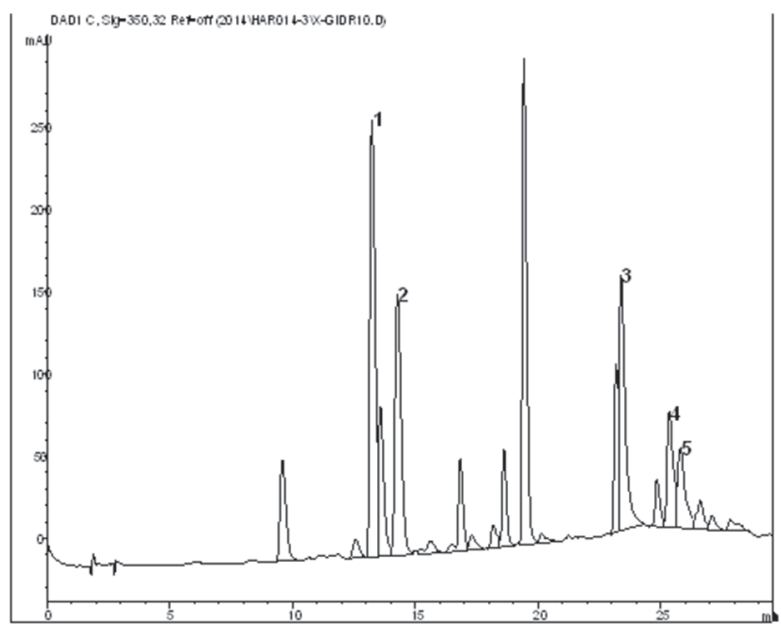

(B)

Fig. 1. Graphical results of HPLC investigation of phenolic compounds in plum leaves extract before (A) and after hydrolysis (B) 
Table 1. The phenolic composition of dry extract from plum leaves $(n=3)$

\begin{tabular}{|lll|c|c|c|}
\hline \multirow{2}{*}{ № } & \multirow{2}{*}{ Compounds } & \multicolumn{2}{c|}{ Before hydrolysis } & \multicolumn{2}{c|}{ After hydrolysis } \\
\cline { 3 - 5 } & $\begin{array}{c}\text { Retention time } \\
\text { min }\end{array}$ & $\begin{array}{c}\text { Content, } \\
(\mathrm{mg} / 100 \mathrm{~g})\end{array}$ & $\begin{array}{c}\text { Retention time, } \\
\text { min }\end{array}$ & $\begin{array}{c}\text { Content } \\
(\mathrm{mg} / 100 \mathrm{~g})\end{array}$ \\
\hline 1 & Caffeic acid derivative & 9.41 & $413.36 \pm 5.02$ & - & - \\
3 & Chlorogenic acid & 13.06 & $2436.89 \pm 25.01$ & 13.14 & $749.19 \pm 9.02$ \\
4 & Chlorogenic acid derivative & 13.44 & $681.42 \pm 8.20$ & - & - \\
5 & Caffeic acid & - & - & 14.20 & $224.10 \pm 2.08$ \\
6 & Rutin & 19.96 & $926.32 \pm 11.13$ & - & - \\
7 & Kaempferol-3-O-glycoside & 21.53 & $327.88 \pm 4.08$ & - & - \\
8 & Isoramnetin-3-O-glycoside & 21.81 & $311.20 \pm 3.02$ & - & - \\
9 & Quercetin & - & - & 23.52 & $311.13 \pm 3.14$ \\
10 & Kaempferol & - & - & 25.46 & $115.54 \pm 2.28$ \\
11 & Isoramnetin & - & - & 25.80 & $119.44 \pm 2.30$ \\
\hline
\end{tabular}

Table 2. Monosaccharide composition of dry extract from the plum leaves $(n=3)$

\begin{tabular}{l|c|c|}
\hline \multirow{2}{*}{ Monosaccharide } & \multicolumn{2}{|c|}{ Content, \% } \\
\cline { 2 - 3 } & $\begin{array}{c}\text { Before } \\
\text { hydrolysis }\end{array}$ & $\begin{array}{c}\text { After } \\
\text { hydrolysis }\end{array}$ \\
Glucose & $0.26 \pm 0.01$ & $0.76 \pm 0.01$ \\
Galactose & - & $0.51 \pm 0.01$ \\
Rhamnose & $3.84 \pm 0.08$ & $4.88 \pm 0.08$ \\
\hline
\end{tabular}

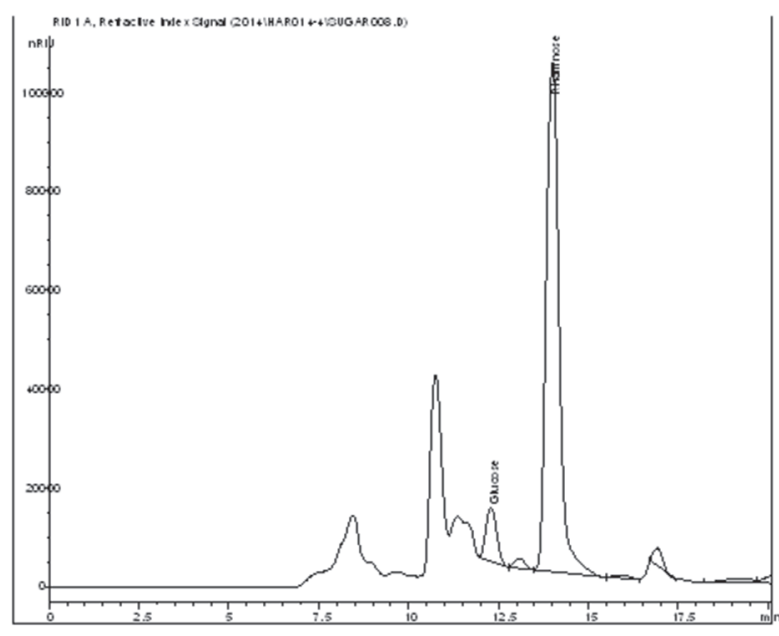

A creased that indicates the presence of glycosides as rhamnosides and galactosides of phenolic compounds. In the main, rhamnose was present as free sugar, glucose was present as a component of glycosides, whereas galactose was present as a part of glycosides only.

The content of chlorogenic acid was the highest in the extract. This compound is widely distributed

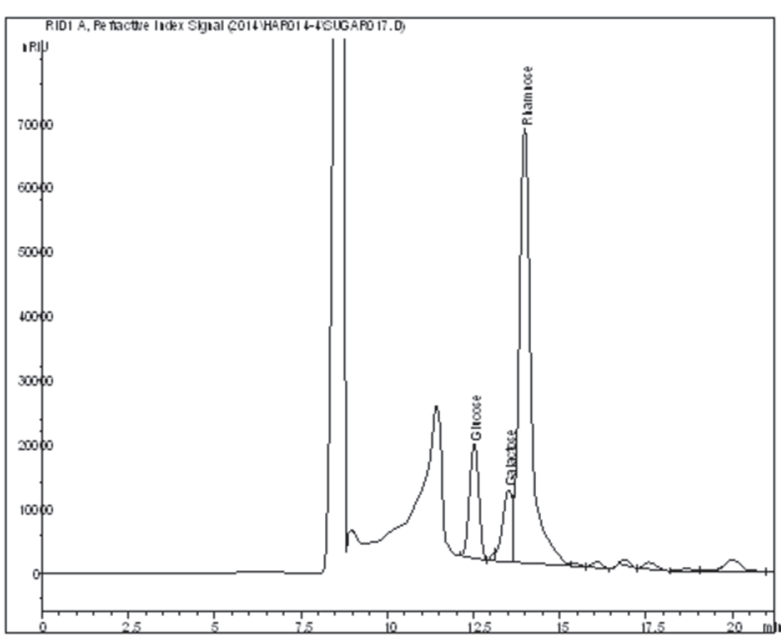

B

Fig. 2. Graphical results of HPLC investigation of monosaccharides in plum leaves dry extract before (A) and after hydrolysis (B)

Evidently, after hydrolysis, free galactose appeared, the amount of glucose and rhamnose in- in fruits and leaves. Therewith, the established antioxidant effect of the plum leaves dry extract in our 
previous studies may be due to the high content of the hydroxicinnamic acids together with flavonoids (1). This assumption is confirmed by other researchers. For example, it was demonstrated in vitro and in vivo that chlorogenic acid has anxiolytic effects coupled with antioxidant activity; in vitro, chlorogenic acid protected granulocytes from oxidative stress (10).

The amount of rutin was highest, compared with other flavonoids glycosides. It is known that rutin has a wide range of pharmacological properties (e.g., antioxidative activity) that have been exploited in human medicine and nutrition. Conventionally, it is used as an antimicrobial, antifungal, and antiallergic agent. However, current research has shown its multi-spectrum pharmacological benefits for the treatment of various chronic diseases, such as cancer, diabetes, hypertension, and hypercholesterolemia (11).

The obtained results will be used in standardization of the plum leaves dry extract and for further pharmacological investigation of its activity.

\section{CONCLUSIONS}

Investigation of chemical composition of the dry extract from plum leaves was carried out before and after hydrolysis by HPLC. Four flavonoid glycosides and three hydroxycinnamic acids were established. The prospects of creating a new drug with antioxidant activity were confirmed.

\section{REFERENCES}

1. Zagayko A, Senuyk I, Lenchyk L, Galimullin R. Study of antioxidant activity of the extract from plum ordinary leaves. Ukrainian biopharmaceutical journal. 2014; 1(30) : 25-28. Ukrainian.

2. Qaiser J, Naveed A.The pharmacological activities of prunes: The dried Plums. Journal of Medicinal Plants Research. 2011; 5(9): 1508-1511.

3. Pharmaceutical encyclopedia. $2^{\text {nd }}$ ed.: Chairman Ed. Council Chernykh V.P. Kiev: «MORION»; 2010. 1290 p. Ukrainian.

4. Vovk G, Koshovyi O, Komissarenko A. Study of dry extract phenolic compounds of sage leaves, obtained by complex processing after tincture production. Collection of scientific works of staff members of NMAPE. 2014; 4:237 - 40.
5. Chen L., Hrazdina G. Structural aspects of anthocyanin-flavonoid complex formation in plant color. Phytochemistry. 1981;20:297-3.

6. Court W. H. P. L. C. reverse phase of naturally occurring phenolic compounds. J. Chromatogr. 1977;130:287-91.

7. Mabry T, Markham K, Thomas M. The Systematic Identification of Flavonoids. New York: SpringerVerlag; 1970.

8. Mc. Murrough I, Hennigan G, Loughrey M. Quantitative analysis of hop flavonols using H.P.L.C. J. Agric. Food Chem. 1982;30:1102-6.

9. Kovaleva A, Abdulkafarova E. Phenolic compounds from Potentilla anserine. Chemistry of Natural Compounds. 2011;47(3):446-7.

10. Bouayed J, Rammal H, Dicko A, Younos C, Soulimani R. Chlorogenic acid, a polyphenol from Prunus domestica (Mirabelle), with coupled anxiolytic and antioxidant effects. J Neurol Sci. 2007;262(1-2):77-84.

11. Al-Dhabil N, Arasu1 M, Park C. Ha, Park S. Un. An up-to-date review of rutin and its biological and pharmacological activities. EXCLI Journal. 2015;14:59-63. 